\title{
Acanthamoeba castellanii, a Predator of Cyanobacteria
}

\author{
By S. J. L. WRIGHT, ${ }^{*}$ K. REDHEAD† AND HELEN MAUDSLEY \\ Microbiology Group, School of Biological Sciences, University of Bath, Bath BA2 7AY, U.K.
}

(Received 10 December 1980; revised 2 February 1981)

Acanthamoeba castellanii was isolated from soil and water as a predator of cyanobacteria. Several strains of $A$. castellanii consumed cyanobacteria but there were differences in predatory activity between strains. The unicellular Gloeocapsa alpicola and filamentous Anabaena flos-aquae were particularly susceptible to predation. Under optimal conditions the amoebae fed voraciously but they encysted when the cyanobacterial food supply was exhausted. Predation was initiated by engulfment of whole cyanobacteria and, in the case of Anabaena flos-aquae, severance of filaments. This was followed by digestion in vacuoles.

\section{INTRODUCTION}

Living cyanobacteria (blue-green algae) are attacked by many micro-organisms, including bacteria, viruses, actinomycetes and chytrid fungi (Stewart \& Daft, 1976, 1977). The range of antagonists of cyanobacteria has been extended by the isolation of antibiotic-producing filamentous fungi (Redhead \& Wright, 1978, 1980). Although there have been reports that some amoebae can feed on cyanobacteria (Leidy, 1879; Comandon \& de Fonbrune, 1936; Prowse, 1968; Haberey, $1973 a, b$; Cook et al., 1974; Cook \& Ahearn, 1976; Old \& Darbyshire, 1978), little attention has been given to soil amoebae, especially the common hartmanellid types. Indeed, Heal \& Felton (1970) and Ho \& Alexander (1974) indicated that cyanobacteria are unsuitable as food for small amoebae.

Whilst isolating cyanobacterial-lysing microbial agents by plaque formation on lawn cultures (Redhead \& Wright, 1978), we frequently noticed that plaques contained small amoebae predatory on the cyanobacteria. The amoebae were identified as Acanthamoeba castellanii, and briefly reported by Wright et al. (1978). We were surprised to note that apparently only one other worker (Yamamoto, 1978) has made similar observations concerning cyanobacterial lysis plaques, but in this case the amoebae were not identified. Lazcano et al. (1977) isolated an Acanthamoeba sp. from cultures of the cyanobacterium Oscillatoria. We have now made further studies on the distribution and cyanobacteriapredating activity of acanthamoebae and present the findings in this paper.

\section{METHODS}

Cultivation of cyanobacteria. Axenic cultures of the following cyanobacteria were obtained from the Culture Centre of Algae and Protozoa (C.C.A.P.), Cambridge: (a) unicellular types - Anacystis nidulans 1405/1 and Gloeocapsa alpicola 1430/1; (b) filamentous types - Anabaena cylindrica 1403/2a, Anabaena flos-aquae 1403/13a, Nostoc muscorum 1453/12, Oscillatoria tenuis 1459/4, Plectonema boryanum $1446 / 2$ and Tolypothrix tenuis $1482 / 3 \mathrm{a}$. Batch liquid cultures $(100 \mathrm{ml}$ ) were grown in $250 \mathrm{ml}$ Erlenmeyer flasks. Medium D plus $\mathrm{H}_{3}$ micro-elements solution (K \& M medium; Kratz \& Myers, 1955) was used for the filamentous cyanobacteria Anabaena flos-aquae, $N$. muscorum, P. boryanum and $T$. tenuis. The modified medium of Hughes et al.

† Present address: National Institute for Biological Standards and Control, Holly Hill, Hampstead, London NW3 6RB, U.K.

$\ddagger$ Present address: Daniel Thwaites \& Co. Ltd, P.O. Box 50, Star Brewery, Blackburn BB1 5BU, U.K. 
(Allen, 1968) was used for the unicellular cyanobacteria Anacystis nidulans and G. alpicola and also for Anabaena cylindrica and $O$. tenuis. Cultures were incubated at $30 \pm 1^{\circ} \mathrm{C}$ in an orbital shaker $\left(100 \mathrm{rev} . \mathrm{min}^{-1}\right)$, except for $O$. tenuis which was grown in static culture, and provided with constant fluorescent white illumination (1500lx). Cyanobacteria were maintained on agar $(1.5 \%, \mathrm{w} / \mathrm{v})$ slants of the same media under the same temperature and light conditions.

Isolation of predatory amoebae from soil and water samples. Surface soil samples were collected from several locations in the winters of 1977, 1978 and 1980 . Soil samples $(10 \mathrm{~g})$ were dispersed in 1 litre sterile tap water and $0.5 \mathrm{ml}$ samples of further dilutions were gently spread over the surface of $1 \mathrm{~d}$ lawn cultures (Redhead \& Wright, 1978) of Anacystis nidulans, Anabaena cylindrica, Anabaena flos-aquae and $N$. muscorum in Petri dishes. Alternatively, six soil crumbs (approx. $5 \mathrm{~mm}$ diam.) were placed directly on the lawn and each was then eluted with one drop of K \& M medium. Freshwater samples were collected in 1976 and in the early months of 1980. Samples $(0.5 \mathrm{ml})$ of the water and dilutions were spread over lawn cultures ( $2 \mathrm{~d})$ of Anabaena flos-aquae, $O$. tenuis and $N$. muscorum. Lawn cultures were incubated at $30^{\circ} \mathrm{C}$ or at room temperature with constant fluorescent illumination $(1500 \mathrm{~lx})$ and examined daily for the appearance of plaques, which were usually present after 4-6 d. Microscopic examination of material removed from the periphery of plaques revealed whether or not predatory amoebae were present. In some cases bacteria and fungi were also detected, but the larger plaques commonly contained vast numbers of amoebae and their cysts, sometimes exclusively so. Material from the edge of plaques containing amoebae was transferred to fresh lawns of the appropriate cyanobacteria and development of further plaques was monitored. The plaques contained apparently identical amoebae with fine, tapering pseudopodia; these amoebae produced cysts with a well-defined polygonal endocyst and rippled ectocyst.

Purification and identification of amoebae. Amoebae from the plaques were examined by Dr F. C. Page, Curator of Protozoa, C.C.A.P., who identified them as the common soil amoeba Acanthamoeba castellanii. This identification was subsequently confirmed with axenic cloned material by Dr A. J. Griffiths, University College, Cardiff, and by ourselves using the key of Page (1976). The amoebal clones were obtained by transferring individual cysts from plaques to fresh lawn cultures using a micromanipulator. One clone, designated AC-31, was used extensively in further studies.

Cultivation of amoebae. The following additional axenic amoebal cultures were obtained from the C.C.A.P.: Acanthamoeba castellanii 1501/1a, A. castellanii 1501/2a, A. castellanii 1534/3, A. palestinensis $1547 / 1$ and A. comandoni 1501/5. Acanthamoeba castellanii (Neff strain) was obtained from Dr A. J. Griffiths, University College, Cardiff. The amoebae were grown in batch cultures $(10 \mathrm{ml})$ from $1 \mathrm{ml}$ inocula in $50 \mathrm{ml}$ Erlenmeyer flasks in peptone/glucose/yeast extract (PGY) medium (Chagla \& Griffiths, 1974) at $30^{\circ} \mathrm{C}$ in a reciprocating shaker ( 80 oscillations $\min ^{-1}$ ).

Predatory activity. This was determined by plaque formation on cyanobacterial lawns to which $0.01 \mathrm{ml}$ samples of exponentially growing amoebal cultures were applied. Drops initially spread to cover an area about $5 \mathrm{~mm}$ in diameter without affecting the lawns. Predation was also monitored by the disappearance of cyanobacteria from liquid cultures inoculated with 0.1 vol. amoebal suspension using the wells of divided Petri dishes (Repli dishes, Sterilin). For both experimental systems, the dishes were incubated either at room temperature with $1440 \mathrm{~lx}$ illumination or at $30^{\circ} \mathrm{C}$ with $1500 \mathrm{~lx}$ and examined daily up to $12 \mathrm{~d}$. Predation was confirmed by microscopic observations on wet mount and slide culture preparations.

Microscopy. Phase contrast and differential interference contrast (Nomarski) optics on a Leitz Orthoplan photomicroscope were used for observing amoebal predation of cyanobacteria in wet mount preparations and phase contrast for slide culture preparations.

Cyanobacterial cell density; chlorophyll determination. Samples $(5 \mathrm{ml})$ from cultures in liquid media were centrifuged $(2000 \mathrm{~g}, 30 \mathrm{~min})$ and the cells were resuspended in $4 \mathrm{ml}$ boiling methanol for $10 \mathrm{~min}$. The resulting suspension was centrifuged $(2000 \mathrm{~g}, 30 \mathrm{~min})$, and the supernatant was removed and made up to $5 \mathrm{ml}$ with methanol. Absorbance due to the chlorophyll in the extract was determined at $665 \mathrm{~nm}$ against a methanol reference.

\section{RESULTS}

\section{Distribution of acanthamoebae predatory upon cyanobacteria}

Acanthamoebae were detected as cyanobacterial predators in samples of soil and water taken from 30 sites in the vicinity of Bath. The sites included fallow and cultivated soils, lake mud, river sediment and canal, lake and pond waters. Amoebae were more frequently detected as the plaque-forming agent than were fungi, bacteria and actinomycetes combined. Of the species of cyanobacteria used as 'host' lawn cultures, most plaques were formed on Anabaena flos-aquae and Anacystis nidulans. Although most amoebae fitted the description of Acanthamoeba castellanii, some representatives of $A$. polyphaga and $A$. palestinensis were also recognized on the basis of cyst morphology (Page, 1976). 
Table 1. Ability of acanthamoebae to prey upon a range of cyanobacteria

\begin{tabular}{|c|c|c|c|c|c|c|c|}
\hline & & & & Plaque & diameter" & & \\
\hline & & Acantham & oeba castel & llanii strai & & & \\
\hline Cyanobacteria & AC-31 & $\begin{array}{c}\text { Neff } \\
\text { (Griffiths) }\end{array}$ & $1501 / 1 \mathrm{a}$ & $1501 / 2 \mathrm{a}$ & $1534 / 3$ & A. palestinensis & A. comandoni \\
\hline Anacystis nidulans & +++ & ++ & ++ & + & +++ & - & - \\
\hline Gloeocapsa alpicola & +++ & ++ & +++ & ++ & +++ & - & - \\
\hline Anabaena flos-aquae & +++ & +++ & +++ & + & +++ & - & - \\
\hline Anabaena cylindrica & - & - & - & - & - & - & - \\
\hline Plectonema boryanum & $-(\dagger)$ & $-(\dagger)$ & $-(\dagger)$ & $-(\dagger)$ & + & - & - \\
\hline Nostoc muscorum & - & - & - & - & - & - & - \\
\hline Tolypothrix tenuis & - & - & - & - & - & - & - \\
\hline Oscillatoria tenuis & - & - & - & - & - & - & - \\
\hline
\end{tabular}

* Plaque diameter was scored after $12 \mathrm{~d}$ incubation at room temperature: - , no plaques;,$+ \leqslant 15 \mathrm{~mm}$; ,$++ 16-20 \mathrm{~mm} ;+++,>20 \mathrm{~mm}$. ( + ) Ingestion followed by rejection.

\section{Prey range of acanthamoebae}

Several acanthamoebae were examined to compare their ability to prey upon a range of cyanobacteria with that of the typical isolate obtained in this laboratory, A. castellanii AC-31. Predatory activity was tested in triplicate using cyanobacterial lawn cultures and cyanobacterial liquid cultures in Repli dishes. Predatory activity (Table 1) scored after 2, 5, 7, 9 and $12 \mathrm{~d}$ according to plaque formation in lawn cultures and discoloration and clearing in liquid cultures was confirmed microscopically. Similar results were recorded for lawn and liquid cultures and only those for the lawn cultures are given in Table 1. Predatory activity was variable and was confined to the five $A$. castellanii strains.

Both unicellular cyanobacteria were readily predated, but excepting Anabaena flos-aquae and to some extent $P$. boryanum, the filamentous species were not. Variation was observed in the plaques formed by different amoebae. Strain AC-31 formed rapidly spreading clear zones fringed by a region of partial cyanobacterial destruction. Most of the other strains produced well-defined plaques which did not increase in size after 7 to $9 \mathrm{~d}$, whilst the clear plaques caused by strain 1501/1a on $G$. alpicola lawns were encircled by a region of smaller cleared zones. In both lawn and liquid cultures G. alpicola and Anabaena flosaquae were consistently the most suitable prey. None of the amoebae ingested Anabaena cylindrica, $N$. muscorum, $T$. tenuis or $O$. tenuis, even after incubation for $18 \mathrm{~h}$. However, the amoebae were usually closely associated with the cyanobacteria and often moved along their filaments in apparent preference to the free liquid phase.

Acanthamoeba castellanii strains AC-31 and 1501/2a were unable to predate any of a selection of 11 species of unicellular and filamentous eukaryotic algae in lawn culture. However, the strains Neff (Griffiths), 1501/1a and 1534/3 did prey upon the unicellular Chlamydomonas eugametos, C. oblonga, C. reinhardii, Chlorella vulgaris and Coelastrum microporum to a limited extent. The amoebae showed greater predation of autoclaved $\left(121^{\circ} \mathrm{C}, 15 \mathrm{~min}\right)$ Anabaena flos-aquae than non-autoclaved filaments, probably due to the liberation of single and short chains of cells by the heating. In all cases where cyanobacteria or algae were not predated, complete encystment of the amoebae was evident $2 \mathrm{~d}$ after their inoculation on to such lawns.

\section{Factors affecting amoebal predation of cyanobacteria}

These experiments were confined to A. castellanii strains AC-31, Neff (Griffiths) and $1501 / 1 \mathrm{a}$, with $G$. alpicola and Anabaena flos-aquae. When suspensions $(0.2 \mathrm{ml})$ of amoebal cells $(1501 / 1 \mathrm{a})$ in the exponential phase of growth were added to $G$. alpicola cultures $(2.8 \mathrm{ml})$ so that the resulting number of amoebae ranged from $1.93 \times 10^{4}$ to $9.67 \times 10^{4} \mathrm{ml}^{-1}$, the 


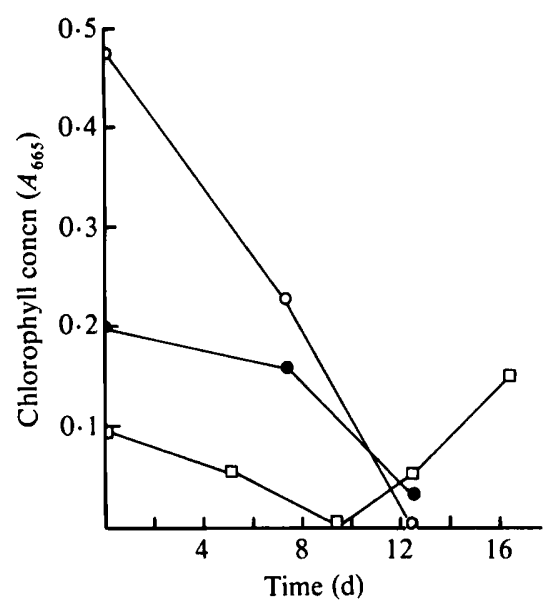

Fig. 1

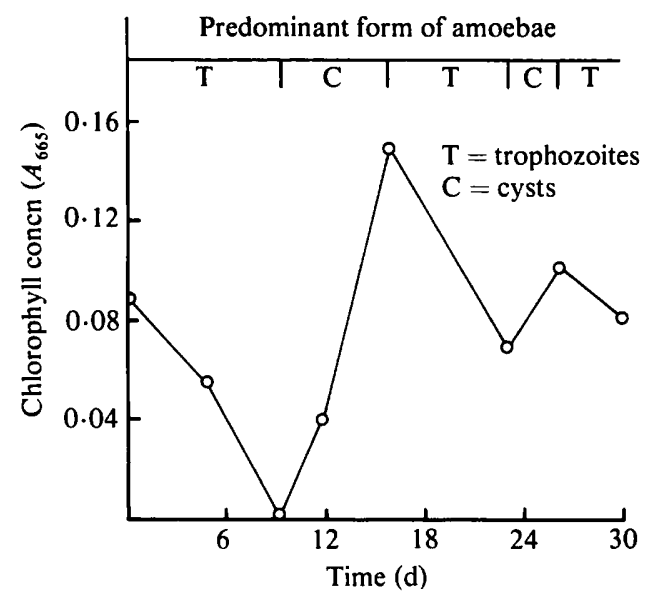

Fig. 2

Fig. 1. Predation of Gloeocapsa alpicola by Acanthamoeba castellanii. Gloeocapsa alpicola cells were suspended in fresh medium $\left(95 \mathrm{ml}\right.$ in $250 \mathrm{ml}$ flasks) at three different cell densities giving $A_{600}$ readings in a $1 \mathrm{~cm}$ cell of $2.73(0), 1.20(O)$ and $0.94(\square)$. Each flask was inoculated with $5 \mathrm{ml}$ A. castellanii (Griffiths, Neff strain) suspension and incubated statically at $30^{\circ} \mathrm{C}$. At intervals the G. alpicola population density was determined by measuring the chlorophyll content of $5 \mathrm{ml}$ samples, as described in Methods.

Fig. 2. Oscillations in Gloeocapsa alpicola populations following predation by Acanthamoeba castellanii. These were monitored in the system with the lowest initial cyanobacterial population (Fig. 1). At intervals the $G$. alpicola population density was determined by measuring the chlorophyll content of $5 \mathrm{ml}$ samples, as described in Methods.

rate of disappearance of the cyanobacteria was directly related to the number of amoebae present.

The initial rate of disappearance of $G$. alpicola and Anabaena flos-aquae from liquid cultures in the presence of $A$. castellanii $1501 / 1$ a increased with temperature $\left(13^{\circ} \mathrm{C}<\right.$ $23^{\circ} \mathrm{C}<30^{\circ} \mathrm{C}$ ) when incubated in the light, although after $5 \mathrm{~d}$ there was little difference in rate. Similar results were obtained with dark incubation. Amoebal encystment did not occur until the prey was virtually exhausted. After this, re-growth of Anabaena flos-aquae occurred from surviving cells in the light but not in the dark. Predatory activity of strain AC-31 was generally apparently greater in the dark than in light, probably due to more rapid cyanobacterial proliferation in the light, especially at $30^{\circ} \mathrm{C}$.

Microscopic examination of the $A$. castellanii-induced plaques on Anabaena flos-aquae showed that a few isolated amoebae were present 2 to $3 \mathrm{~mm}$ beyond the visible plaque periphery but none were beyond this zone. At the leading edge of the plaque there were large numbers of amoebal trophozoites. Most amoebae were actively engulfing filaments or contained several cyanobacterial cells in different stages of digestion. The outermost $5 \mathrm{~mm}$ of the plaques contained some amoebal cysts among the trophozoites, but the 'older' centre part was typically devoid of vegetative cyanobacterial cells and comprised many amoebal cysts and debris together with some indigestible heterocysts and akinetes. The non-confluent plaques formed on green algae tended to disappear after $7 \mathrm{~d}$, when the amoebae had encysted.

\section{Predator-prey oscillation and amoebal proliferation}

It was repeatedly noticed during maintenance of $A$. castellanii AC-31 in liquid cultures of Anabaena flos-aquae that after disappearance of most of the cyanobacteria due to predation, there was re-growth of cyanobacteria. With further incubation oscillations in amoebal and cyanobacterial dominance occurred. More detailed observations of such oscillations were subsequently made with $G$. alpicola and the Neff (Griffiths) strain of $A$. castellanii. The 

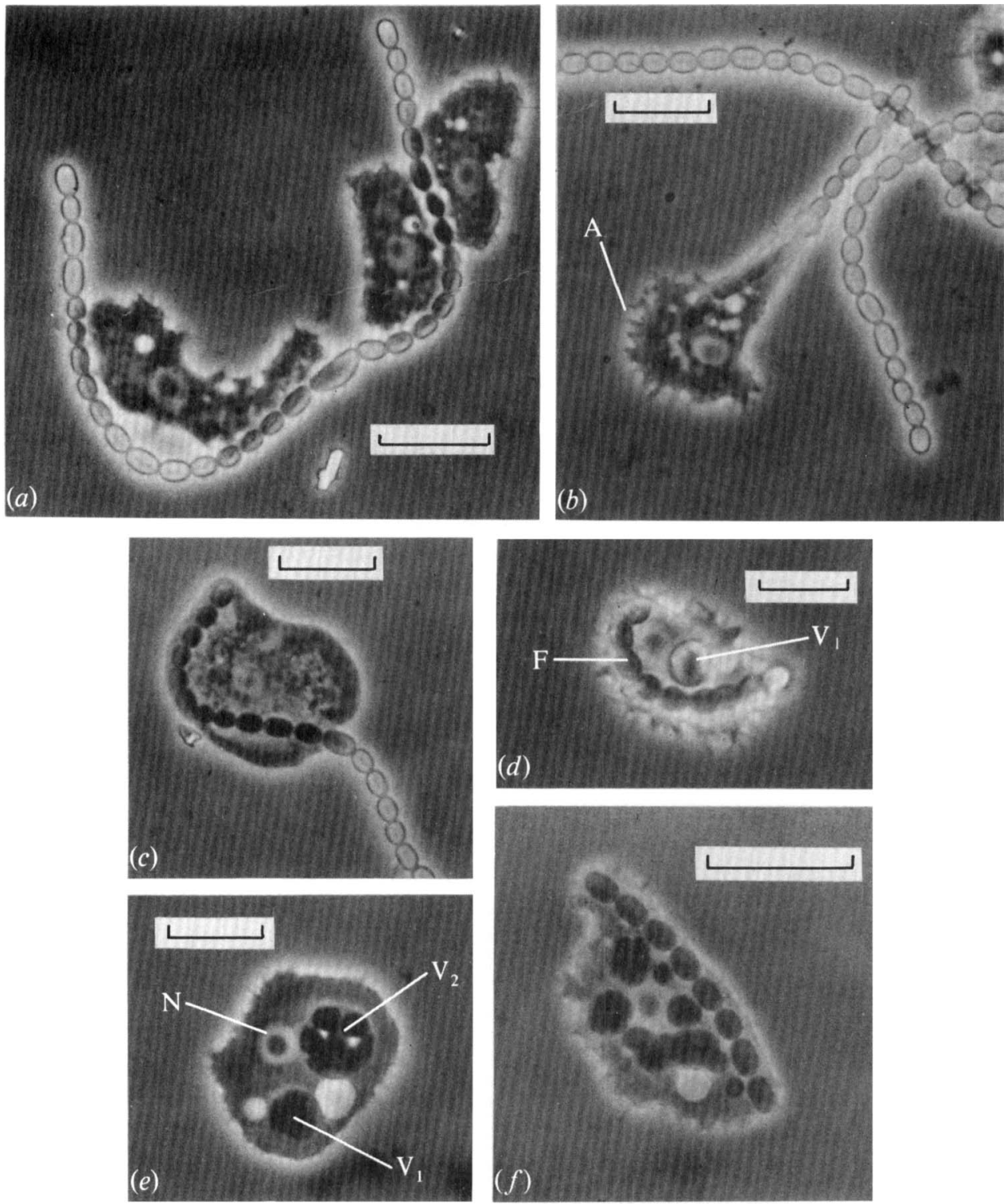

Fig. 3. Some stages in the predation and digestion of Anabaena flos-aquae by $A$. castellanii. (a) Acanthamoebae roaming the surface of an Anabaena flos-aquae filament. (b) Extension of amoebal pseudopodium to engulf part of a filament: the amoeba has prominent acanthopodia (A). (c) Ingestion of 11 Anabaena flos-aquae cells, with bending of the filament. (d) An amoeba with a vacuole $\left(\mathrm{V}_{1}\right)$ containing Anabaena flos-aquae cells in an advanced stage of digestion, together with a recently engulfed filament (F) of 9 cells. (e) The same amoeba as in $(d) 60 \mathrm{~min}$ later: the remains of the filament are now in a vacuole $\left(\mathrm{V}_{2}\right)$ adjacent to the nucleus $(\mathrm{N})$. ( $f$ ) An amoeba containing at least 25 Anabaena flos-aquae cells at different stages of digestion. The bar markers represent $20 \mu \mathrm{m}$.

decline in cyanobacterial population density in liquid cultures inoculated with $A$. castellanii (Fig. 1) was followed by amoebal encystment. Whilst no further changes were seen in flasks originally containing the higher $G$. alpicola densities (Fig. 1), re-growth of G. alpicola occurred in the flask with the lowest initial density after the amoebae had encysted. At this stage $G$. alpicola cells adhered in masses to aggregated amoebal cysts. This was followed by excystment of the amoebae and subsequent decline in the $G$. alpicola cells due to predation 
by trophozuites. Such population changes were repeated once again (Fig. 2) upon further incubation although the oscillation amplitude diminished with time.

Extensive replication of the amoebae occurred on lawns of susceptible cyanobacteria. Amoebae feeding upon cyanobacteria were often observed to be dividing and the high number of cysts in the plaques could not be explained by migration from the original inoculum. The numbers of $A$. castellanii AC-31 increased from an initial $3.5 \times 10^{3} \mathrm{ml}^{-1}$ to $3.8 \times 10^{4} \mathrm{ml}^{-1}$ after $5 \mathrm{~d}$ incubation at $30^{\circ} \mathrm{C}$ in liquid Anabaena flos-aquae culture.

\section{The predation and digestion process}

The following account describes events in the predation of Anabaena flos-aquae filaments. The stages, shown in Fig. 3, were photographed with the Neff (Griffiths) strain of $A$. castellanii and typify those seen with all predatory amoebae examined.

As an amoeba approached a filament and made contact with it (Fig. $3 a$ ) numerous fine acanthopodia were produced by which the amoeba aligned itself with and often surrounded the filament whilst seeking the terminal cell, to which it became attached. Engulfment of the filament then occurred by the extension of a cylindrical pseudopodium (Fig. $3 b$ ), the amoeba changing shape markedly. Occasionally amoebae commenced ingestion away from the ends of filaments, bending the filament and folding the two parts together before engulfing the two parallel sections. Pseudopodial extension was often interrupted for a few minutes and occasionally some of the filament re-emerged before engulfment proceeded, but complete escape from amoebae was also seen. Filaments were sometimes engulfed at both ends simultaneously by different amoebae, with one or both achieving ingestion. Usually 4 to 8 cells were engulfed but the number could be up to 15 . In the latter cases the amoebae were engulfing filaments three to four times their own length which required considerable contortions by the amoebae. In order to accommodate such a mass of cyanobacteria, typically the first (distal) engulfed cell was turned round when it contacted the opposite interior face of the amoeba, followed by coiling of much of the remaining filament (Fig. $3 c$ ). The filament was then severed and the portion not ingested was freed (Fig. $3 d$ ). The time from initiation of engulfment to this stage varied between 15 and $60 \mathrm{~min}$.

The amoeba then made slow movements in the same position, continually re-orientating the ingested filament. After a further 5 to $15 \mathrm{~min}$ the filament started to break at several points and cells separated. The initial break was usually between the first and second cell in a filament. Most of the cells had lost their linear arrangement about $30 \mathrm{~min}$ after entry and later were grouped in one or more spherical clumps (Fig. $3 e$ ); it was then evident that they were enclosed in vacuoles. The vacuoles were initially green but became discoloured as digestion proceeded. Complete digestion could take several hours, depending on the number of cells ingested. Undigested cyanobacterial debris was expelled.

Amoebae began to move freely again once the cyanobacterial cells were confined in vacuoles and they were then able to engulf more cells whilst still digesting those captured earlier. Amoebae have been seen with at least 25 Anabaena flos-aquae cells in various stages of digestion (Fig. $3 f$ ).

\section{DISCUSSION}

The indirect evidence of wide distribution, frequent isolation from soil and water samples, and voracious appetite for some cyanobacteria including a filamentous form, prompt the suggestion that acanthamoebae may be involved in the natural regulation of cyanobacteria. Whether they operate upon blooms and, if so, whether they could be used for biological control of blooms has yet to be determined.

The present observations illustrate variation in the ability of $A$. castellanii strains to prey upon cyanobacteria (and green algae), which cannot be explained by differences in the size 
or shape of the prey. Heal \& Felton (1970) and Ho \& Alexander (1974) also reported variation in the suitability of prey for this amoeba, but their results concerning the susceptible cyanobacteria differ from those presented here. This may be due to experimental techniques but it is still surprising since some of the same amoebal strains were examined. Heal \& Felton (1970) used the strain isolated by Neff which is presumably synonymous with strain 1501/1a in our study, whilst Ho \& Alexander (1974) used a strain obtained from Dr A. J. Griffiths, Cardiff. This, also a Neff strain, is identical to that supplied by Dr Griffiths for our own study and may have the same origin as the 1501/1a strain. Ho \& Alexander (1974) found that cyanobacteria were unsuitable in promoting growth of this amoeba.

Generally, unicellular cyanobacteria were more susceptible to predation than filamentous forms, with the notable exception of Anabaena flos-aquae. Some of the cyanobacteria not ingested included branched filamentous (Tolypothrix tenuis) and motile (Oscillatoria tenuis) forms. Heterocysts and akinetes resisted amoebal digestion. Although there was no ingestion of several filamentous cyanobacteria, the amoebae tended to move over the filaments in apparent preference to moving freely in the bulk liquid phase. A similar observation was made by Picken (1937).

We gratefully acknowledge the assistance of C. Varnals and P. J. Baccarini in these studies and the co-operation of $\operatorname{Dr}$ A. J. Griffiths. The work was partly supported by a Science Research Council research studentship awarded to K. R.

\section{REFERENCES}

AlLEN, M. M. (1968). Simple conditions for growth of unicellular blue-green algae on plates. Journal of Phycology 4, 1-4.

Chagla, A. H. \& Griffiths, A. J. (1974). Growth and encystation of Acanthamoeba castellanii. Journal of General Microbiology 85, 139-145.

Comandon, J. \& DE Fonbrune, P. (1936). Mécanisme de l'ingestion d'Oscillaires par des amibes. Enregistrement cinematographique. Comptes rendus des séances de la Société de biologie 123, 1170-1172.

Cook, W. L. \& AhearN, D. G. (1976). Natural control of Anabaena blooms by the amoeba Asterocaelum anabaenophilum sp.nov. In Distributional History of the Biota of the Southern Appalachians. Part IV: Algae and Fungi Biogeography Systematics and Ecology, pp. 71-80. Edited by B. C. Parker and M. K. Roane. Charlottesville: University of Virginia Press.

Cook, W. L., Ahearn, D. G., Reinhardt, D. J. \& REIBER, R. J. (1974). Blooms of an algophorous amoeba associated with Anabaena in a fresh water lake. Water, Air and Soil Pollution 3, 71-80.

Haberey, M. Von $(1973 a$ ). Die Phagocytose von Oscillatorien durch Thecamoeba sphaeronucleolus. I. Lichtoptische Untersuchung. Archiv für Protistenkunde 115, 99-110.

Haberey, M. Von (1973 $b$ ). Die Phagocytose von Oscillatorien durch Thecamoeba sphaeronucleolus. II. Elektronemikroskopische Untersuchung. Archiv für Protistenkunde 115, 111-124.

HeAl, O. W. \& Felton, M. J. (1970). Soil amoebae: their food and their reaction to microflora exudates. In Animal Populations in Relation to their Food Resources, pp. 145-161. Edited by A. Watson. Oxford: Blackwell Scientific Publications.
Ho, T. S.-S. \& Alexander, M. (1974). The feeding of amoebae on algae in culture. Journal of Phycology 10, 95-100.

KratZ, W. A. \& Myers, J. (1955). Nutrition and growth of several blue-green algae. American Journal of Botany 42, 282-287.

Lazcano, M. M. C., Benitez, G. D. \& Nieto, R. A. DE LA (1977). Aspectos metodológicos en el estúdio de 'amoebas limax'. Revista ibérica de parasitologia 37, 329-344.

LEIDY, J. (1879). Freshwater Rhizopods of North America. Report of the U.S. Geological Survey of the Territories, vol. 12. Washington: Government Printing Office.

Old, K. M. \& Darbyshire, J. F. (1978). Soil fungi as food for giant amoebae. Soil Biology and Biochemistry 10, 93-100.

PAGE, F. C. (1976). An Illustrated Key to Freshwater and Soil Amoebae. Freshwater Biological Association, Scientific Publication No. 34. Ambleside: Freshwater Biological Association.

Picken, L. E. R. (1937). The structure of some protozoan communities. Journal of Ecology 25, 368-384.

Prowse, G. A. (1968). Algal records. Report of the Tropical Fish Culture Research Institute, Malacca, 22.

REDHEAD, K. \& WRIGHT, S. J. L. (1978). Isolation and properties of fungi that lyse blue-green algae. Applied and Environmental Microbiology 35, 962969.

Redhead, K. \& Wright, S. J. L. (1980). Lysis of the cyanobacterium Anabaena flos-aquae by antibioticproducing fungi. Journal of General Microbiology 119, 95-101. 
Stewart, W. D. P. \& DAFT, M. J. (1976). Algallysing agents of freshwater habitats. In Microbiology in Agriculture, Fisheries and Food, pp. 63-90. Edited by F. A. Skinner \& J. G. Carr. London: Academic Press.

Stewart, W. D. P. \& DafT, M. J. (1977). Microbial pathogens of cyanophycean blooms. In Advances in Aquatic Microbiology, vol. 1, pp. 177-218. Edited by M. R. Droop \& H. W. Jannasch. London: Academic Press.
Wright, S. J. L., Forrest, H. S., Redhead, K. \& VARNALS, C. W. (1978). Predation of blue-green algae by Acanthamoeba castellanii. Journal of Protozoology 25, $11 \mathrm{~B}$.

Yамамото, Y. (1978). Detection of algal-lysing biological agents in lakes by the soft-agar overlayer technique. Japanese Journal of Limnology 39, 9-14. 